\title{
Stabilization Control Techniques for a Roadway in Deep High-Stress Soft Surrounding Rock
}

\author{
HU Jin-tan ${ }^{1,2}$, LIN Deng-ge ${ }^{1,2}, \quad$ ZHAO Ru-mei ${ }^{1,2}$ \\ ${ }^{1}$ School of Civil Engineering and Architecture, Shandong University of Science and Technology \\ ${ }^{2}$ Shandong Provincial Key Laboratory of Civil Engineering Disaster Prevention and Control, \\ Qingdao 266590, China)
}

\begin{abstract}
In order to solve the instability of roadways in deep high-stress soft rock, this paper proposed four supporting schemes for controlling the deformation of surrounding rock by using the horizontal roadway of $\mathbf{- 9 8 0 m}$ level refrigeration underground chamber in Xinhe Mining. Grouting and full section anchoring support, grouting and enclosed U36 steel support, grouting + enclosed U36 steel and full section anchoring support, and grouting + enclosed U36 steel + full section anchoring + masonry lining are proposed to control the deformation of surrounding rock according to the specific conditions of the mine. In view of the field engineering geological analysis, combined with laboratory tests, field monitoring, theoretical analysis and numerical simulation, the mechanism of deformation instability and supporting measures were studied. The numerical simulation results show that the grouting and enclosed U36 steel + full section anchoring support is more ideal, and achieved good economic and technical results.
\end{abstract}

Keywords - Soft rock roadway, Deep high stress, mine pressure monitoring, curve fitting

With the continuous increase of the depth of coal mining, coal production process has encountered a series of outstanding problems. Expansion of soft rock is particularly prominent. When the rock mass is disturbed, especially when the water is in the water, the lithology changes greatly. This has a huge expansion pressure on the construction of the building, and seriously affect the stability of the project. Deep mining is different from the shallow mining conditions, especially in the deep part of the extremely complex geological structure, soft rock high stress, weak and broken surrounding rock conditions of mining. It is very difficult to maintain the roadway in the deep conditions, and it will put forward higher and more stringent requirements for supporting design.

In view of the deep roadway support problem, domestic and foreign experts and scholars have conducted a lot of research, and achieved a series of results, However, the research on the problem of the chamber supporting of soft broken surrounding rock in deep mine is few. In view of the current situation of coal, coal enterprises to bear repaired for many times repeated investment. Therefore, to explore deep weak broken surrounding rock of chamber deformation instability mechanism, in search of economic reasonable supporting technology become the urgent need to resolve important issues.

\section{I.ENGINEERING SURVEY}

With a burial depth over 1,000 meters, the horizontal roadway of Xinhe Mining's $-980 \mathrm{~m}$ horizontal refrigerating chamber is under high stresses and, due to other complicating factors, the roadway deformation would be great and the support would be very challenging. The -980 horizontal chamber is subject to a maximum principal stress of $28.41 \sim 28.66 \mathrm{MPa}$, which is nearly horizontal, forming an included angle less than $20^{\circ}$ with the horizontal plane. The uniaxial compressive strength of the rock is $20.24 \mathrm{MPa}$, as established in a direct rock jacking test, making shear failure highly probable, and the tensile strength is $2.25 \mathrm{MPa}$; the rock is generally of poor strength. This region is characterized by high ground stress levels yet the surrounding rock is of poor 
strength, with the ground stress being 1.40 1.42 times the uniaxial compressive strength of the surrounding rock. High ground stress and low surrounding rock strength are therefore found to be the major causes leading to roadway deformation and destabilization.

\section{FLAC ${ }^{3 \mathrm{D}}$ NUMERICAL SIMULATION}

2.1 Establishment of three dimensional numerical model a model of $50 \mathrm{~m} \times 10 \mathrm{~m} \times 40 \mathrm{~m}$ in dimensions was created, for which the field ground stresses were simulated by applying external forces to the surface of the model. Given the ground stress testing results, the numerical simulation was performed using a vertical external load of $24.8 \mathrm{MPa}$ and a horizontal external load of 28.5MPa. For the simulation, the constitutive model was based on Mohr-Coulomb theory.FLAC ${ }^{3 \mathrm{D}}$ three-dimensional model is shown in Figure 1.

In light of the field situation and the actual circumstances,

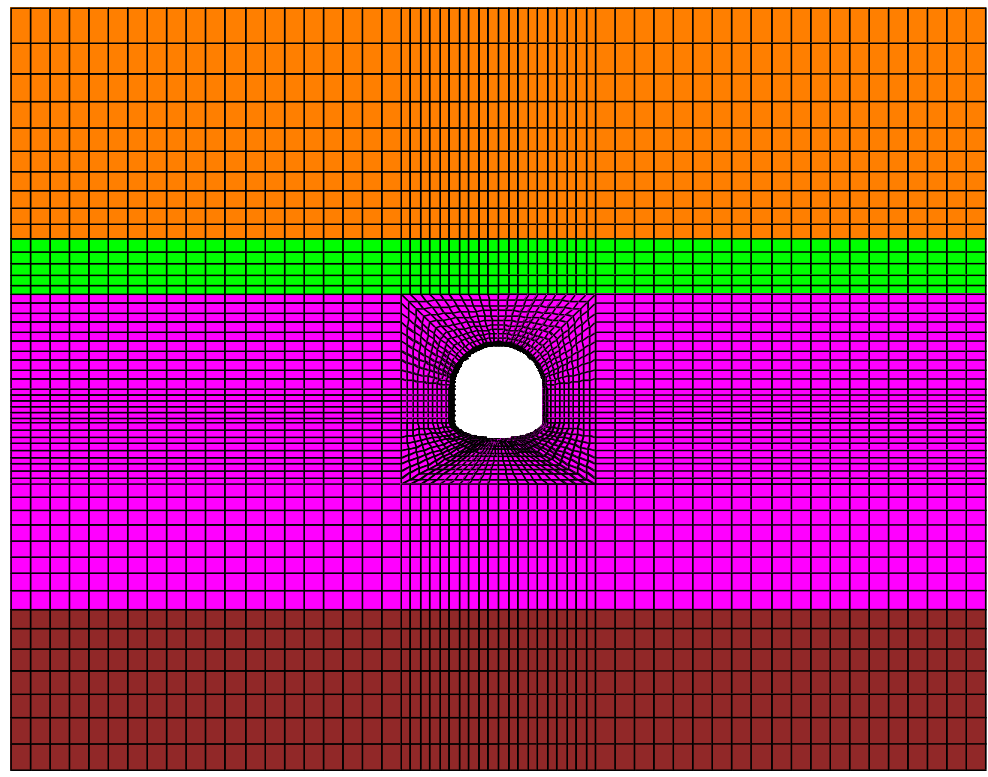

Fig. 1 numerical model diagram

The physical and mechanical properties and parameters machine. Results are shown in Table 1. Basic mechanical of the rock material were made available using a tri-axial parameters of bolt and U36 steel as shown in Table 2,3. compressive test on a laboratory MTS rock servo testing

Table 1 Rock mechanical parameter table

\begin{tabular}{ccccccc}
\hline \multirow{2}{*}{ name } & $\begin{array}{c}\text { density } \\
/ \mathrm{kg} / \mathrm{m}^{3}\end{array}$ & $\begin{array}{c}\text { Tensile } \\
/ \mathrm{MPa}\end{array}$ & cohesion /MPa friction angle & $\begin{array}{c}\text { Shear modulus } \\
/ \mathrm{GPa}\end{array}$ & $\begin{array}{c}\text { Bulk modulus } \\
/ \mathrm{GPa}\end{array}$ \\
\hline Mudstone & 2400 & 2.25 & 1.5 & 30 & 2.65 & 3.5 \\
Sandstone & 2550 & 3.1 & 2.6 & 27 & 3.34 & 4.6 \\
\hline
\end{tabular}

Table 2 Mechanical parameter table of anchors

\begin{tabular}{ccccccccc}
\hline name & $\begin{array}{c}\text { Elastic } \\
\text { modulus } \\
/ \mathrm{GPa}\end{array}$ & $\begin{array}{c}\text { tensile } \\
/ \mathrm{kN}\end{array}$ & $\begin{array}{c}\text { prestress } \\
/ \mathrm{kN}\end{array}$ & $\begin{array}{l}\text { diameter } \\
/ \mathrm{mm}\end{array}$ & $\begin{array}{c}\text { cohesion } \\
/(\mathrm{kN} / \mathrm{m})\end{array}$ & $\begin{array}{c}\text { Internal friction rigidity } \\
\text { angle } /{ }^{\circ}\end{array}$ & $\begin{array}{c}\text { Outer } \\
/ \mathrm{MPa}\end{array}$ & $\begin{array}{c}\text { circumference } \\
/ \mathrm{mm}\end{array}$ \\
\hline figure & 200 & 130 & 60 & 20 & 2000 & 30 & 17 & 110 \\
\hline
\end{tabular}

Table 3 Mechanical parameter table of U36

\begin{tabular}{llccccc}
\hline \multirow{2}{*}{ model } & $\begin{array}{l}\text { Sectional } \\
\text { area } / \mathrm{cm}^{2}\end{array}$ & $\begin{array}{c}\text { theoretical weight Inertia moment Elasticmoduls/G } \\
/(\mathrm{kg} / \mathrm{m})\end{array}$ & $/ \mathrm{cm} 4$ & $\begin{array}{c}\text { Tensile } \\
\text { rigidity } / \mathrm{kN}\end{array}$ & $\begin{array}{c}\text { Flexural rigidity } \\
/\left(\mathrm{kN} \cdot \mathrm{m}^{2}\right)\end{array}$ \\
\hline $\mathrm{U} 36$ & 44.69 & 35.87 & 928.65 & 200 & $9.138 \times 10^{5}$ & 1857.3 \\
\hline
\end{tabular}




\subsection{Numerical simulation of supporting structure}

The numerical simulation of the following four kinds of supporting methods are carried out for the -980 level refrigeration chamber of New River mining industry

(1)Solution I full-section anchoring (anchored cable) support and grouting mode, Supporting parameters: $\Phi 20 \times 2200 \mathrm{~mm}$ full thread steel bolt,anchoring spacing $800 \times 800 \mathrm{~mm}, \quad \Phi 21.8 \mathrm{~mm} \times 6200 \mathrm{~mm}(1 * 17$ strands $)$ anchored cable spacing $800 \times 1600 \mathrm{~mm}$ 。

(2)Solution II Grouting+enclosed U36 section steel+full-section anchoring (anchored cable)steel support model. Supporting parameters: U36 Steel shed and Closed bottom arch, Spacing shed $800 \mathrm{~mm}$, Pouring concrete anti bottom arch.

(3) Solution III Grouting+enclosed U36 section

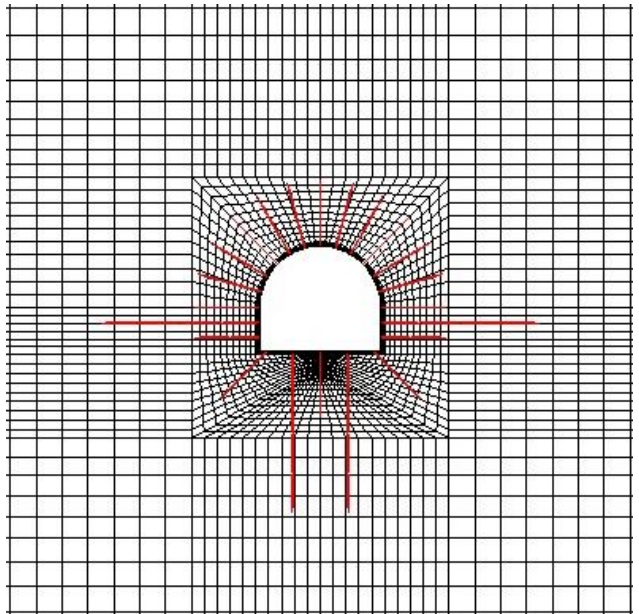

(1)

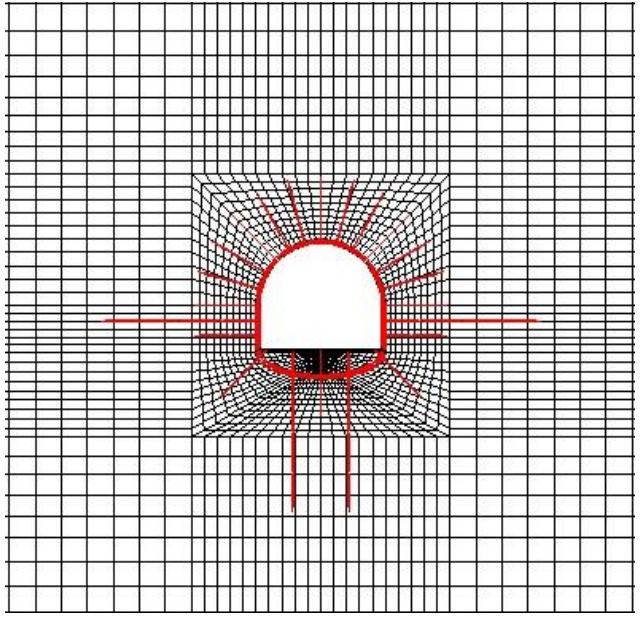

(3) steel+full-section anchoring (anchored cable). Supporting parameters:U36 Steel shed and Closed bottom arch, Spacing shed $800 \mathrm{~mm}$, Pouring concrete anti bottom arch; $1000 \mathrm{~mm}$ lengthening anchorage, $\Phi 20 \times 2200 \mathrm{~mm}$ full thread anchor rod @ $800 \times 800 \mathrm{~mm}$, and $\Phi 21.8 \mathrm{~mm} \times 6200 \mathrm{~mm} \quad(1 * 17$ strands $)$ tendon, anchoring

(4) Solution IV: Grouting+enclosed U36 section steel + full-section anchoring (anchored cable) + masonry crown. Supporting parameters: U36 steel shed, anchoring spacing $800 \times 800 \mathrm{~mm}+$ closed bottom arch; $\Phi 20 \times 2200 \mathrm{~mm}$ full thread anchor rod@ @800×800mm, and $\Phi 21.8 \mathrm{~mm} \times 6200 \mathrm{~mm}(1 * 17$ strands) tendon, anchoring spacing $800 \times 1600 \mathrm{~mm}$. $500 \mathrm{~mm}$ thick reinforced concrete masonry crown, with reinforcement Ф20mm@300*300mm.

The simulation model of the four schemes is shown in Fig. 2

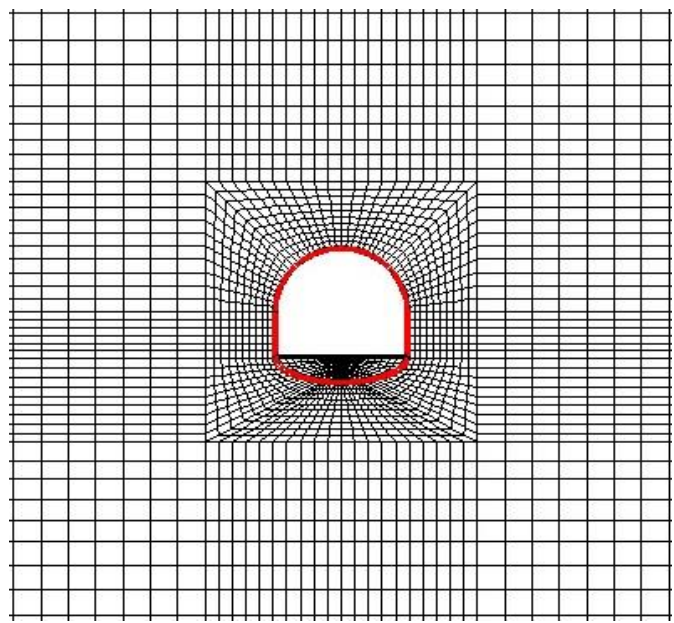

(2)

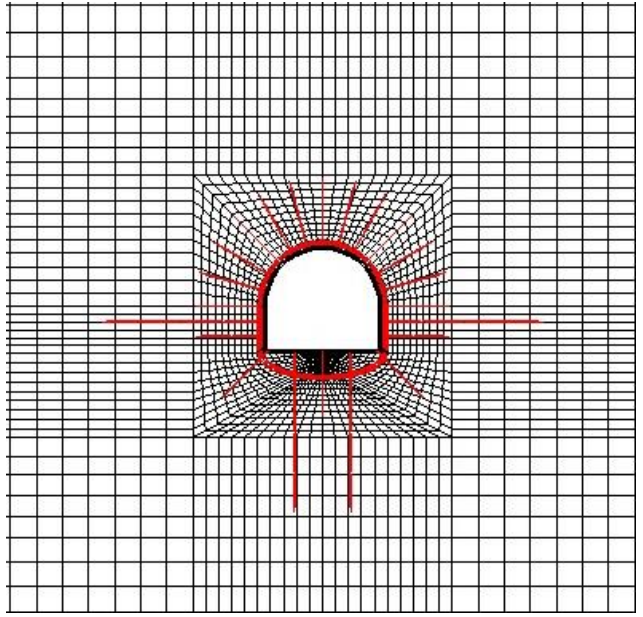

(4)

Fig. 2 Simulation Scheme 


\section{III.ANALYSIS OF NUMERICAL SIMULATION}

3.1 Analysis of displacement evolution law after excavation

Different types of post-excavation support were simulated. The patterns of vertical displacement and settlement evolution as subsequently simulated for the roof, the left side wall, and the floor of the roadway under different conditions are shown in Fig. 3.

From Fig. 3 it is found by comparing the roof settlement amounts that the four models behave in a similar pattern in roof settlement, with a minimal influence experienced from excavation when the distance is at $10 \mathrm{~m}$; the four solutions produce a roof settlement of $1279.8 \mathrm{~mm}, 795.6 \mathrm{~mm}, 400.7 \mathrm{~mm}$, and $214.3 \mathrm{~mm}$ respectively. Model I produces the largest settlement among the four models, and the roadway will be

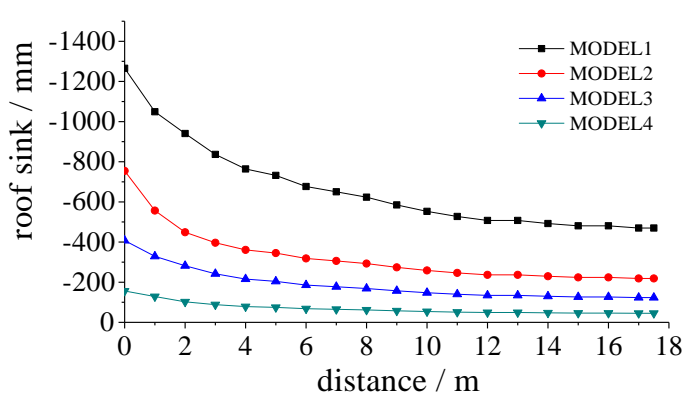

(a) Roof subsidence evolution curve

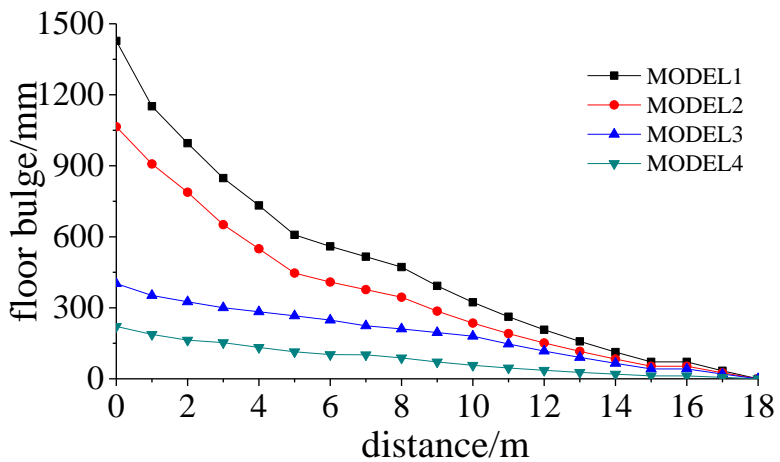

(c) Evolution curve of bottom drum

Fig. 3 Displacement curves of surrounding rock after tunnel excavation

3.2 Analysis of the evolution law of stress after excavation

Fig. 4 shows the post-excavation surrounding rock stress evolution pattern. As is evident, excavation may influence the roof rock stress within a range up to $9 \mathrm{~m}$, with Model I having the largest influence variation (up to $3.1 \mathrm{Mpa}$ ). In Model III, the stress variation is relatively small, as low as $0.9 \mathrm{MPa}$. The surrounded by extremely unstable rock; the subsidence of the model III or IV is relatively small, and the stability of the surrounding rock is in accordance with the requirements .The left side wall develops a maximum displacement of $685 \mathrm{~mm}$, $538.7 \mathrm{~mm}, 211.2 \mathrm{~mm}$, and $100.5 \mathrm{~mm}$ respectively in the four support solutions. The displacement in the left side wall tends to stabilize down from $8 \mathrm{~m}$ away outwards, where the influence of excavation is less; model III or IV, the displacement is relatively small, and the change of displacement is same.It is clear from the floor displacement variation that the floor heave is maximum in a scope from the cutting face to a level $14 \mathrm{~m}$ below the roadway bottom; the four models have a maximum floor heave of $1427.5 \mathrm{~mm}$, $1064.8 \mathrm{~mm}, 332.2 \mathrm{~mm}$, and $241.3 \mathrm{~mm}$ respectively, but the influence of excavation becomes minimal when the distance exceeds $14 \mathrm{~m}$.

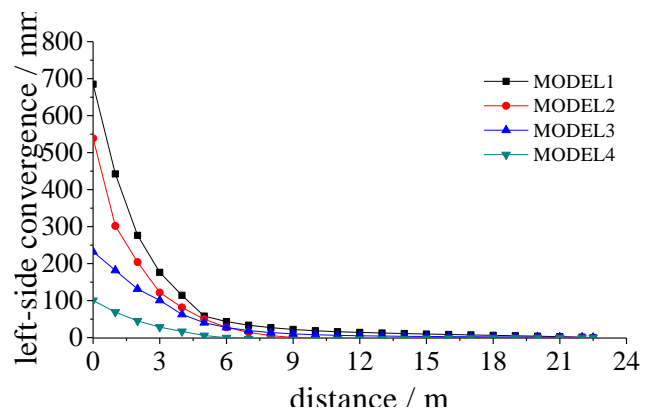

(b) roadway's sides Close evolution curve post-excavation stress variation in the left side diminishes with the distance and the effect of excavation becomes minimal when the distance reaches $10 \mathrm{~m}$, Model I producing a stress variation of 3.0MPa, the largest of the four models. The stress variation, 1.0MPa, occurs in Model III.The floor rock stress varies in a similar pattern to the roof or the left ride, and $11 \mathrm{~m}$ is found to be the critical distance, beyond which the influence 
of excavation becomes minimal; Model III produces relatively small stress variation. After analysis of the displacement and stress evolution pattern of the models corresponding to the

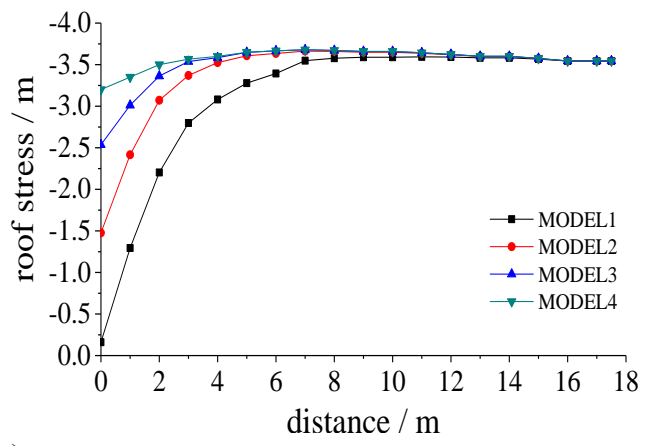

(a) Stress evolution law of roof covering rock four solutions, and reference to the actual economic and technical solution, III has been retained as the optimal choice.

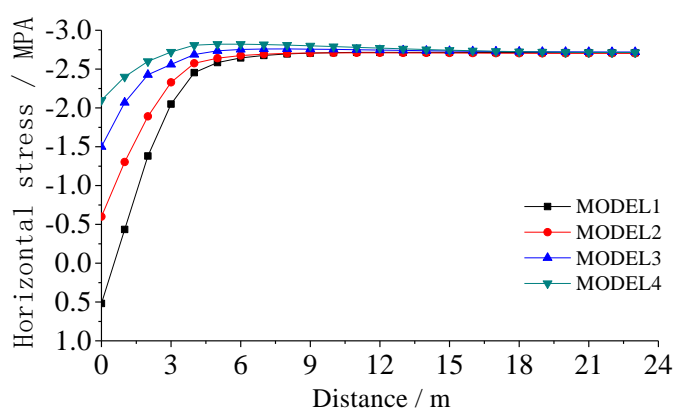

(b) Stress evolution law of the left side

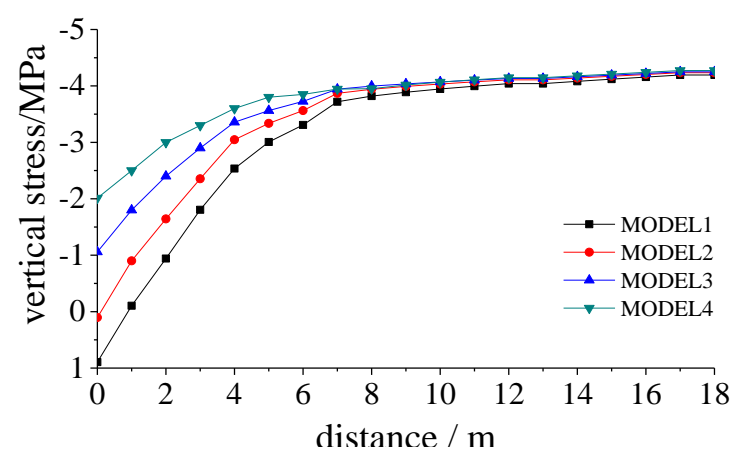

(c) Stress evolution law of floor strata

Fig. 4 Stress evolution law of surrounding rock after tunnel excavation

\section{ENGINEERING APPLICATIONS}

From the geotechnical condition, the monitored roadway deformation and failure patterns, and the FLAC ${ }^{3 \mathrm{D}}$ numerical analysis and practical economic and technical conditionsof different support solutions for Xinhe Mining's $-980 \mathrm{~m}$ refrigerating chamber, it arrives that the optimal support solution is grouting + enclosed U36 section steel + full-section anchor (anchored cable).The supporting scheme is shown in Figure 5.

\section{V.MINE PRESSURE MONITORING}

Following the support works of the $-980 \mathrm{~m}$ refrigerating chamber that couple grouting and anchoring, the roadway was monitored for its floor to bottom narrowing amount and its roadway's sides narrowing amount using a crisscross pattern of monitoring points.Monitoring results are shown in figure 6 .

\section{VI.CONCLUSIONS}

(1) With the help of FLAC3D software, an insight was provided into the mechanical properties of the surrounding rock in the excavation of a Xinhe Mining's roadway in deep hi-stress soft rock. Deep Roadway Influenced by excavation, and the front end of roadway surrounding rock are plastic failure, Destroy the first from the key parts (such as corner of roadway's sides , bottom corner, etc.) and then to the entire roadway instability; The deformation and failure of the surrounding rock of the road is obviously larger than the two side and the top plate.

(2) The more distant away from the cutting face, the less is the deformation in the roof, the left side wall and the floor, for which the critical distance of influence is $10 \mathrm{~m}, 8 \mathrm{~m}$, and $14 \mathrm{~m}$ respectively; the stress value stabilizes down as the distance from the free face increases, the critical distance in this regard being $9 \mathrm{~m}, 10 \mathrm{~m}$, and $11 \mathrm{~m}$ respectively for the roof, the left side wall, and the floor. 


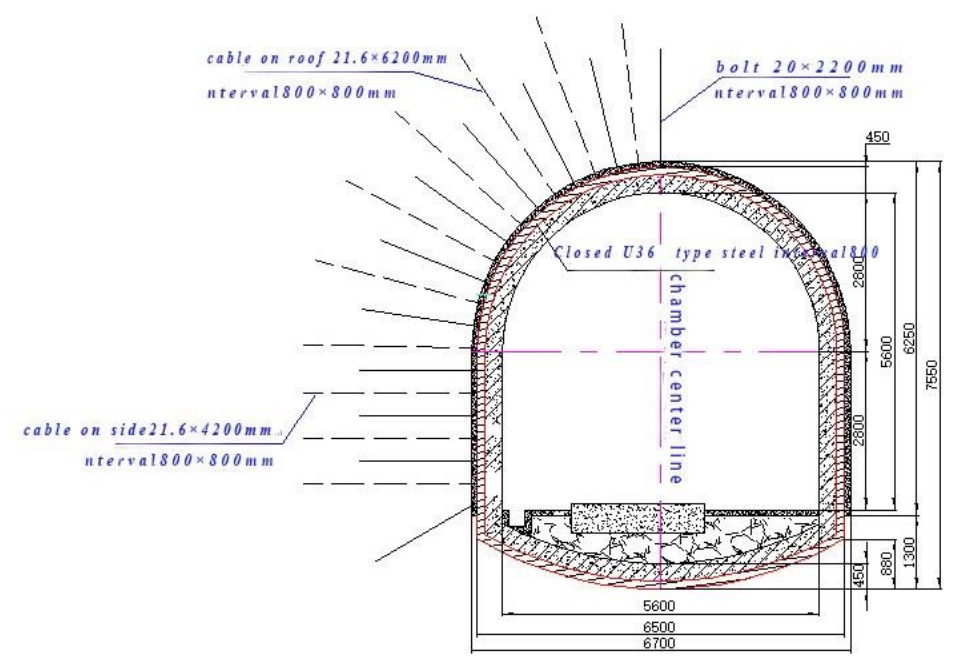

Fig. 5 bolting and grouting support scheme

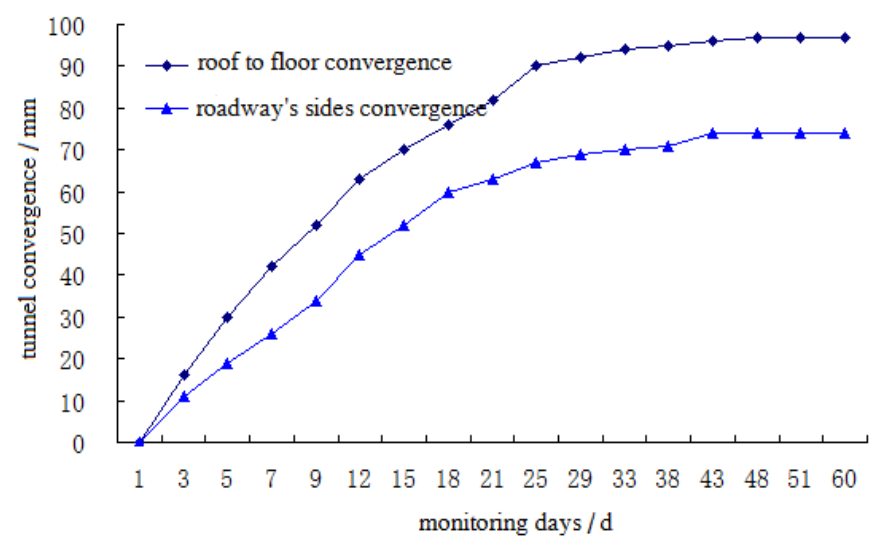

Fig. 6 displacement of roadway surrounding rock

(3) Four support solutions have been proposed to control surrounding rock deformation having regard to the actual coal mine conditions, they are: grouting + full-section anchoring support, grouting + enclosed U36 section steel support, grouting + enclosed U36 section steel + full-section anchoring support, and grouting + enclosed U36 section steel + full-section anchoring + masonry crown. The solutions were compared for their performance and economic technical conditions of the century in the coal mines, subsequently, grouting + enclosed U36 section steel + full-section anchoring was retained, which provided optimal support parameters.

(4) The surrounding rock deformation pattern of the test section as monitored in real time during normal service attested to the efficacy of grouting + enclosed U36 section steel + full-section anchoring in controlling the deformation of a roadway in deep hi-stress soft rock.

\section{REFERENCES}

[1] Yang Jian. Control technology of surrounding rock of roadway surrounding rock in high pressure and soft thick mudstone [J]. Coal Mine 
Safety, 2011,8 (57): 57-59. (in Chinese)

[2] Wang Jiong, Guo Zhibiao, Ma Chengrong et al. Study on bolt mesh cable coupling support technology in deep mining roadway [J]. Coal Science and Technology, 2015,43 (5): 17-21. (in Chinese)

[3] Sun Xiaoming, Wang Dong, Yang Jun, et al. Xinan Coal Mine return air Shimen soft rock roadway constant resistance large deformation coupling support supporting measures [J]. Chines Journal of Rock Mechanics and Engineering, 2014,33 (S2): 4129-4138. (in Chinese)

[4] Jiang Yaodong, Wang Hongwei, et al. Research on complementary control support technology of mining roadway in soft rock [J].Chines Journal of Rock Mechanics and Engineering, 2009,28 (12): 2383-2390. (in Chinese)

[5] Attewell P B, Tunneling and site investigations[J]. Geotechnical Engineering of Hard Soils/SoftRocks, 1993, 320(3):1767- 790.

[6] Wu Aiqing, Ren.DDA numerical model and its preliminary application in rock mass engineering [J]. Chinese Journal of Rock Mechanics and Engineering, 1997 (5): 411-417. (in chines)

[7] Meng Xiangrui, Gao Zhaoning. The supporting measures for mining roadway of soft rock with high stress in deep mine [J]. Coal Mine Safety, 2007,6 (69): 69-72. (in Chinese)

[8] Yang Yongkang, Li Chunxu et al. Study on failure mechanism and control measures of coal roadway with large thickness mudstone roof [J]. Chinese Journal of Rock Mechanics and Engineering, 2011,30 (1): 58-68. (in Chinese)
[9] Chen Yanguang, Lu Shiliang. Control of surrounding rock of coal roadway in China [M]. Xuzhou: Publishing House of China University of Mining and Technology, 1994 (in Chinese)

[10] He Manchao et al. The mechanics of soft rock engineering [M]. Beijing: Science Press, 2002

[11] Liu Xuehua. Instability mechanism and supporting technology of large section mining roadway [J]. coal science and technology, 2013 (2): 90-92. (in Chinese)

[12] Jager JC, Cook N G W. Fundamentals of Rock Mechanics[M]. Chapman and Hall, London, 1976.

[13] He ManChao. Soft rock tunnel engineering [M]. Xuzhou: China University of Mining and Technology press, 1993 (in Chinese)

[14] He ManChao, king of Haihe River, Sun Xiaoming. Geological journal [J]. Engineering Geological Mechanics of Soft Rock Engineering progress, 2000 (8) (in Chinese)

[15] Hu Jintan, Lin Dengge, Cao Shuai, Zhao Rumei. Broken thick mudstone roof of coal roadway deformation mechanism and control technology [J]. Coal Mine Safety, 2016,06:82-85. (in Chinese)

[16] Qiao Weiguo, Meng Qing bin, Lin Denge, et, Deep soft rock roadway with bolt grouting combined support support technology [J]. Journal of Xi'an University of Science and Technology, 2011, 31 (11): 22-27. (in Chinese) 